\title{
Treatment of elderly patients with refractory/relapsed multiple myeloma: oral drugs adherence and the COVID-19 outbreak
}

\author{
Flávia Dias Xavier ${ }^{1,2}$, Fernando Sergio Blumm Ferreira ${ }^{2}$ and Rodrigo Martins Abreu ${ }^{3}$ \\ ${ }^{1}$ Department of Hematology, Hospital Universitario de Brasilia-UNB/Ebserh, Brasilia, DF, Brazil \\ ${ }^{2}$ Hospital Sirio Libanes, Centro de Oncologia, Unidade Brasilia, Brasilia, DF, Brazil \\ ${ }^{3}$ Medical Affairs, Takeda Distribuidora Ltda., São Paulo, SP, Brazil \\ Correspondence to: Flávia Dias Xavier, email: flavia.dxavier@hsl.org.br
}

Keywords: healthcare; multiple myeloma; adherence; elderly; refractory/relapsed

Received: June 03, 2020

Accepted: October 17, 2020

Published: November 24, 2020

Copyright: @ 2020 Xavier et al. This is an open access article distributed under the terms of the Creative Commons Attribution License (CC BY 3.0), which permits unrestricted use, distribution, and reproduction in any medium, provided the original author and source are credited.

\section{ABSTRACT}

Once the treatment of refractory/relapsed multiple myeloma in the elderly is greatly influenced by the adherence of patients and family members, clinicians should be aware of patients' behavior and lifestyle, as it may influence the individual treatment plan for each patient. Furthermore, treatment with oral chemotherapy is of special value during the COVID-19 outbreak. Multidisciplinary healthcare involvement is crucial in the management of polypharmacy, adverse events and dose adjustment due to comorbidities and natural loss of renal function with age. Oral drugs simplify intake, reduce hospital visits, and improve autonomy and quality of life. However, although oral drugs have advantages, they also transfer control and responsibility from the healthcare professional to the patient, who must be able to understand and follow the directions given. Therefore, patient education and communication with healthcare professionals are critical for adherence.

\section{INTRODUCTION}

Multiple myeloma (MM) is a treatable, although incurable, disease that represents $2 \%$ of malignant neoplasms and affects patients with a median age of 69 years old (two-thirds $\geq 65$ years, one-third $\geq 75$ years and $10 \% \geq 85$ years) $[1,2]$. In Brazil, there are 29 million citizens aged $>60$ years [3], and by 2030, the life expectancy will be 79 years $[4,5]$, with the number of elderly people increasing by $40 \%$ [3]. The incidence of MM follows the population trend. Between 2010 and 2030 , an increase of $57 \%$ is expected among the general population, with an increase of $68 \%$ among people $\geq 65$ years old [6].

The frequent relapses and continuous treatment requirements of MM (Figure 1), together with its prevalence in the elderly population, make the individualization of therapeutic choice essential, with a special focus on adherence to treatment, which may impact patients' physiological and socioeconomic reality [7].

The introduction of new drugs for MM treatment (Figure 2) resulted in an increase in 5-year survival from
$29 \%$ (1990) to $54 \%$ (2015) [1] and an increase in survival time from 3.2 (2001-2005) to 5 years (2006-2010) in patients $>65$ years old [8], but there was no improvement in survival at $>80$ years old $[9,10]$. In addition, out of the ten antimyeloma drugs that have emerged in the last 21 years, seven are oral (Figure 2). In clinical studies, combinations of daratumumab, lenalidomide, and dexamethasone (DRd); carfilzomib, lenalidomide, and dexamethasone (KRd); elotuzumab, lenalidomide, and dexamethasone (ERd); ixazomib, lenalidomide, and dexamethasone (IRd); daratumumab, bortezomib, and dexamethasone (DVd); pomalidomide, bortezomib, and dexamethasone (PVd); and panobinostat, bortezomib, and dexamethasone (Pan-Vd) are more efficacious than the combination of lenalidomide and dexamethasone (Rd) or bortezomib and dexamethasone $(\mathrm{Vd})$ in the treatment of relapsed and/or refractory MM (RRMM) (Table 1), resulting in better responses and increased progressionfree survival (PFS) and overall survival (OS) [11-31].

In this context, the objective of this perspective paper is to review MM management with oral therapies, focusing on adherence in elderly patients with RRMM along with clinical experiences and perspectives in Brazil. 
Table 1: First to third lines of rescue treatment

\begin{tabular}{|c|c|c|c|c|c|c|c|c|}
\hline Studies & $\begin{array}{c}\text { POLLUX } \\
{[11,12,17,29]}\end{array}$ & $\begin{array}{l}\text { ASPIRE } \\
{[26-30]}\end{array}$ & $\begin{array}{c}\text { ELOQUENT-2 } \\
{[13,14,31]}\end{array}$ & $\begin{array}{l}\text { TOURMALINE- } \\
\text { MM1 [15] }\end{array}$ & $\begin{array}{c}\text { CASTOR } \\
{[11,16-18]}\end{array}$ & $\begin{array}{l}\text { ENDEAVOR } \\
{[19,20,30]}\end{array}$ & $\begin{array}{c}\text { OPTIMISMM } \\
{[21]}\end{array}$ & $\begin{array}{l}\text { PANORAMA1 } \\
\text { [22] }\end{array}$ \\
\hline $\begin{array}{l}\text { Experimental versus } \\
\text { Control }\end{array}$ & DRd versus Rd & KRd versus $\mathrm{Rd}$ & ERd versus Rd & IRd versus $\mathrm{Rd}$ & DVd versus Vd & $\mathrm{Kd}$ versus $\mathrm{Vd}$ & PVd versus Vd & $\begin{array}{c}\text { Pan-Vd versus } \\
\text { Vd }\end{array}$ \\
\hline$N$ (patients) & 286 versus 283 & 396 versus 396 & 321 versus 325 & 360 versus 362 & 251 versus 247 & 464 versus 465 & 281 versus 278 & 387 versus 381 \\
\hline OR (\%) & 93 versus $76(s)$ & 87 versus $67(s)$ & 79 versus $66(s)$ & 78 versus $72(s)$ & 83 versus $63(s)$ & 77 versus $63(\mathrm{~s})$ & 82.2 versus 50 & 60.7 versus 54.6 \\
\hline ～VGPR (\%) & 79 versus $48(s)$ & 70 versus $40(s)$ & 35 versus 29 & 48 versus $39(s)$ & 59 versus $29(s)$ & 54 versus $29(s)$ & 52.7 versus 18.3 & 27.6 versus 15.7 \\
\hline$\geq \mathrm{CR}(\%)$ & 51 versus $21(s)$ & 32 versus $9(\mathrm{~s})$ & 5 versus 9 & 12 versus $7(s)$ & 19 versus $9(s)$ & 13 versus $6(s)$ & 15.7 versus 3.9 & 11 versus 6 \\
\hline MRD neg $(<10-5)(\%)$ & 26 versus $6(\mathrm{~s})$ & NR & NR & NR & 7 versus $2(s)$ & NR & NR & NR \\
\hline Median PFS (months) & NA versus 18(s) & 26 versus $17(s)$ & 19 versus $15(\mathrm{~s})$ & 21 versus $15(s)$ & 17 versus $7(\mathrm{~s})$ & 18 versus $9(\mathrm{~s})$ & $\begin{array}{l}11.2 \text { versus } \\
7.1(\mathrm{~s})\end{array}$ & 11 versus $8(s)$ \\
\hline PFS (\%) & $\begin{array}{c}24 \text { months: } \\
68 \text { versus } 41(\mathrm{~s})\end{array}$ & $\begin{array}{c}18 \text { months: } \\
65 \text { versus } 47(\mathrm{~s})\end{array}$ & $\begin{array}{c}48 \text { months: } \\
21 \text { versus } 14(s) \\
24 \text { months: } \\
41 \text { versus } 27(s)\end{array}$ & NR & $\begin{array}{c}18 \text { months: } \\
48 \text { versus } 8(s)\end{array}$ & $\begin{array}{c}18 \text { months: } \\
49 \text { versus } 24(\mathrm{~s})\end{array}$ & NR & $\begin{array}{l}24 \text { months: } \\
21 \text { versus } 8\end{array}$ \\
\hline $\begin{array}{l}\text { Reduction of DP risk/ } \\
\text { death }(\%)\end{array}$ & 63 & 31 & 29 & 25 & 69 & NR & NR & NR \\
\hline $\begin{array}{l}\text { Duration of response } \\
(\%)\end{array}$ & NA versus 17 & 29 versus 21 & 21 versus $17(\mathrm{~s})$ & 21 versus 15 & NA versus 8 & 21 versus 10 & 8.8 versus 4.9 & 13 versus 11 \\
\hline Median OS (months) & NA versus 20 (ns) & 48 versus $40(s)$ & 48 versus $40(s)$ & NA versus NA & NR & 48 versus $40(s)$ & NR & 33.6 versus 30.4 \\
\hline OS (\%) & $\begin{array}{c}12 \text { months: } \\
92 \text { versus } 87(n s)\end{array}$ & $\begin{array}{l}67.1 \text { months: } \\
33 \text { versus } 25(\mathrm{~s})\end{array}$ & $\begin{array}{l}48 \text { months: } 50 \\
\text { versus } 43(\mathrm{nr})\end{array}$ & NR & NR & $\begin{array}{c}37 \text { months: } \\
59 \text { versus } 55(\mathrm{~s})\end{array}$ & NR & NR \\
\hline $\begin{array}{l}\text { Median for the 1st } \\
\text { response (months) }\end{array}$ & 1 versus 1.3 & 1.6 versus 2.3 & 2.8 versus 2.8 & 1.1 versus 1.9 & 0.9 versus 1.6 & 1.1 versus 1.1 & 0.9 versus $1.4(\mathrm{~s})$ & 1.5 versus 2 \\
\hline $\begin{array}{l}\text { Median follow -up } \\
\text { (months) }\end{array}$ & 25.4 & 67.1 & 48 & 23 & 19.4 & 37.5 & 15.9 & 6.5 \\
\hline
\end{tabular}

(ns) = not significant. $(\mathrm{s})=$ significant $(p<0.05)$ (bold). NR = not reported. NA = not available. Abbreviations: significant $(p<0.05)$, s; not reported, NR; not reached, NA; progression-free survival, PFS; overall survival, OS; overall response, OR; very good partial response, VGPR; complete response, CR; minimal residual disease, MRD; versus.

\section{Adherence to oral drugs}

Low adherence may lead to drug resistance; poor response to treatment; disease progression; increased medical appointments, laboratory tests, hospitalizations and death; and increased health costs [32]. In the US, lack of adherence is the largest preventable factor in healthcare cost, accounting for over $\$ 200$ billion/year [33, 34].

Of the seven available myeloma oral medications, four are available in Brazil (melphalan, thalidomide, lenalidomide and ixazomib). However, in the public health system, of which $72,1 \%$ of the population depends exclusively [3], only thalidomide and melphalan are available. Thalidomide is usually combined with cyclophosphamide and dexamethasone as induction for transplant-eligible myeloma patients, while melphalan is combined with prednisone with or without thalidomide as first-line treatment of transplant-ineligible patients. Oral drugs have advantages (Figure 3), but they shift the focus of control and responsibility from the healthcare professional to the patient, who must be able to understand and follow all the directions given by the drug's prescriber. Barriers to adherence are higher for older patients (Figure 4); therefore, we believe that physicians should educate, instruct, and monitor their patients as well as encourage them to adhere to treatment.

We understand that multidisciplinary involvement, especially of pharmacists, is essential in the management of polypharmacy (optimizing efficacy and reducing adverse events (AEs) and drug interactions), as is the cooperation of the family or other supportive social group-especially in the case of elderly patients whose adherence may be compromised by inability to follow the treatment plan, by forgetting to take medications, and by a lack of assistance from third parties in administering medications or accompanying patients to medical appointments, as well as by AEs associated with medication use. In our practice, AEs can also influence medical staff to reduce the dose or withhold the drug. Additionally, treatment is effective only if followed and is followed only if well tolerated.

How to choose the best salvage treatment for elderly patients: balancing efficiency and tolerance to promote adherence

Frailty is an accumulated decline in many physiological systems, resulting in reduced resistance to stressors such as cancer and its treatment in a manner that is unpredictable by the Eastern Cooperative Oncology Group performance status (ECOG); this decline impacts adherence [35].

The International Myeloma Working Group (IMWG) [35] has created a frailty score that predicts mortality and the risk of toxicity in the elderly (Table 2). The IMWG recommends that fit patients receive triple therapy at a full dose or higher (autologous hematopoietic stem cell transplantation (auto-SCT)); that intermediatefit patients receive less intense double or triple treatments 
Table 2: Frailty score $[35,82-84]$

\begin{tabular}{|c|c|c|c|c|c|c|c|}
\hline Factors & Points & & & & & & \\
\hline$\leq 75$ years & 0 & & & & & & \\
\hline $76-80$ years & 1 & & & & & & \\
\hline$>80$ years & 2 & & & & & & \\
\hline \multicolumn{8}{|l|}{ Activities of Daily Living (ADL) $)^{\#}$} \\
\hline$>4$ & 0 & & & & & & \\
\hline$\leq 4$ & 1 & & & & & & \\
\hline \multicolumn{8}{|c|}{ Instrumental Activities of Daily Living (IADL) } \\
\hline$>5$ & 0 & & & & & & \\
\hline$\leq 5$ & 1 & & & & & & \\
\hline Charlson Comorbidity Index (CCI) ${ }^{\# \#}$ & & $N=$ & SG 3 & SLP 3 & Nonhematological & Treatment & Deaths \\
\hline$\leq 1$ & 0 & 869 & years & years & AEs, grade $\geq 3(\%)$ & discontinuity & \\
\hline$\geq 2$ & 1 & $(\%)$ & $(\%)$ & $(\%)$ & & & \\
\hline \multicolumn{8}{|l|}{ Classification: } \\
\hline Fit & 0 & 39 & $84(\mathrm{~s})$ & $48(\mathrm{~s})$ & $22(\mathrm{~s})$ & $17 \%(\mathrm{~s})$ & $10 \%$ \\
\hline Intermediate fitness & 1 & 31 & $76(\mathrm{~s})$ & $41(\mathrm{~s})$ & $26(\mathrm{~s})$ & $21 \%(\mathrm{~s})$ & $14 \%$ \\
\hline Frail & 2 to 5 & 30 & $57(\mathrm{~s})$ & $33(\mathrm{~s})$ & $34(\mathrm{~s})$ & $31 \%(\mathrm{~s})$ & $27 \%$ \\
\hline
\end{tabular}

$(\mathrm{s})=$ significant $(p<0.05)$ (bold). ${ }^{\#}$ Score $(0$ to 6$)-1$ point: Bathing, dressing, using the toilet, transfer, continence and eating. ${ }^{\#}$ Score $(0$ to 8$)-1$ point: phoning, shopping, preparing food, taking care of the house, doing laundry, transportation, taking care of own medications, taking care of finances. (0 to 37) - 1 point: heart attack, heart failure, peripheral arterial disease, stroke, dementia, chronic obstructive pulmonary disease (COPD), collagenosis, peptic ulcer, mild liver disease, uninjured target-organ diabetes. 2 points: hemiplegia, at least moderate renal failure, injured target-organ diabetes, nonmetastatic cancer, leukemia, lymphoma. 3 points: at least moderate liver disease. 6 points: metastatic cancer, AIDS. Available online: http://www. myelomafrailtyscorecalculator.net/Geriatric.aspx.

(reduced dose) [36]; and that frail patients receive double reduced-dose or even palliative/supportive therapy due to the benefits of low toxicity for the survival of very fragile patients.

In the eight Phase III studies (Table 1 and Supplementary Table 1), which compared triple versus double therapy or carfilzomib and dexamethasone $(\mathrm{Kd})$ versus $\mathrm{Vd}$ in RRMM, patients $\geq 65$ years represented half of the population (42-58\%), and up to one-fifth of all participants were $\geq 75$ years old (9-21\%); however, the included patients had ECOG $\leq 2(>90 \%: 0-1)$ and had no significant comorbidities. In most patients (65-74 or $\geq 75$ years), there was a significant gain of PFS in the experimental arm (triple rescue or $\mathrm{Kd}$ ) in relation to the control arm (double therapy or Vd). Triple rescue or Kd therapy may be considered in elderly patients with ECOG scores of $0-1$.

\section{Comorbidities and toxicities}

The IMWG recommends the use of the Chronic Kidney Disease Epidemiology Collaboration equation (preferred) or the Modification of Diet in Renal Disease Study Group equation to assess renal function [37]. In addition to light chain associated renal impairment or hypercalcemia by MM, there is a natural loss of renal function with age, and approximately half of adults $>70$ years old have creatinine clearance $(\mathrm{CrCl})<60 \mathrm{~mL} / \mathrm{min}$ $[38,39]$. Elderly population have a higher incidence of comorbidities with an impact on renal function, such as diabetes and hypertension, as well as higher usage rates of nephrotoxic drugs such as nonsteroidal anti-inflammatory drugs $[38,39]$.

Patients with $\mathrm{CrCl}<30 \mathrm{~mL} / \mathrm{min}$ are underrepresented $(6 \%$ ENDEAVOR and $<1 \%$ TOURMALINE-MM1) in clinical studies. $\mathrm{CrCl}$ of 30 50 or $60 \mathrm{~mL} / \mathrm{min}$ represented a 10 to $30 \%$ of the study population. PFS increased in patients with $\mathrm{CrCl}<60 \mathrm{~mL} /$ min taking DRd, DVd and Kd [12-20, 23, 25-31].

In general, all salvage treatments can be tolerated, as long as the dose is adjusted for renal function (lenalidomide, pomalidomide and ixazomib) to prevent AEs [24, 40-43]. Bortezomib is a tolerable drug in the context of renal failure. Although carfilzomib does not require dose adjustment, there are few data from individuals with $\mathrm{CrCl}<15 \mathrm{~mL} / \mathrm{min}$ [37, 44, 45]. Panobinostat and selinexor do not need dosage adjustments for renal failure, although their dialyzability is unknown $[46,47]$.

In several studies, DVd was associated with higher neutropenia and thrombocytopenia rates than $\mathrm{Vd}$ was (Table 3) [12, 16-18]. Kd was associated with a slight increase in anemia and thrombocytopenia compared to Vd (based ENDEAVOR study) [19, 20, 30]. All triple therapies induced G3/4 anemia at a rate of $14-20 \%$, which did not differ from the rate in the control group (Vd or Rd) [12-23, 25-31]. The DRd [12, 16, 17, 23, 25] and PVd [21] protocols resulted in G3/4 neutropenia at a rate of more than $50 \%$, while $\mathrm{Vd}$ resulted in a rate of $4-9 \%[12,16-18,21-23,25]$. The Pan-Vd and DVd 
protocols were the ones that most resulted in G3/4 thrombocytopenia $(68 \%$ and $45 \%)$ [11, 16-18, 22], while $\mathrm{Kd}$ resulted in $<10 \%$ thrombocytopenia (Table 3) [19, 20,30]. Thalidomide has limited hematological toxicity, but bortezomib, carfilzomib, lenalidomide and alkylating agents often cause thrombocytopenia [48]. Weekly bortezomib reduced the frequency of AEs compared to biweekly bortezomib and is preferred for fragile patients [48-50].

An ASPIRE subanalysis compared patients < 70 years to patients $\geq 70$ years, and the frequencies of AEs $\geq$ grade 3 , such as neutropenia, anemia, and thrombocytopenia, were increased in carfilzomib, lenalidomide, and dexamethasone patients aged $\geq 70$ years $(37 \%, 24 \%$ and $20 \%$, respectively) compared to both the control group $(23 \% ; 21 \% ; 15 \%)$ and KRd patients aged $<70$ years old $(28 \% ; 16 \% ; 11 \%)$ [51]. The use of granulocyte colony stimulating factor (GCSF) and erythropoietin can be considered for the management of neutropenia and anemia, respectively [50].

Peripheral neuropathy (PN) (Table 3) may be caused by comorbidities (e.g., diabetes), MM, or treatment with thalidomide and/or bortezomib [48, 50]; when caused by these medications, it can be cumulative and relates to the duration of exposure $[52,53]$. In RRMM, it is essential to review the AEs of first-line regimens, since melphalan, prednisone and thalidomide can result in $\mathrm{PN}$ at a rate of up to $55 \%(10 \% \mathrm{G} 3 / 4)[48,54,55]$ while bortezomib, melphalan and prednisone (VMP) can result in up to $44 \%$ (14\% G3/4) PN [56]. Subcutaneous weekly infusions of bortezomib significantly reduced $\mathrm{PN}$ without changing the endpoint $[57,58]$. For patients with pre-existing PN or comorbidities that render them unable to tolerate PN, lenalidomide-based regimens are preferable. In such cases, it is necessary to combine proteasome inhibitors, preferably carfilzomib $(<3 \% \mathrm{PN}$ at $<70$ years or $\geq 70$ years) [51] or ixazomib [15], with bortezomib. In current $\mathrm{PN}$, gabapentin, pregabalin or duloxetine and opioids may improve symptoms and contribute to treatment adherence.

In an ASPIRE subgroup analysis comparing patients $<70$ years to those $\geq 70$ years, heart disease $(9 \%)$ and ischemia $(5 \%)$ of grade $\geq 3$ were more frequent in patients $\geq 70$ years $(\mathrm{KRd})$ than in the control group $(\mathrm{Rd})(2 \%$ and $1 \%)$ or in patients $<70$ years $(\mathrm{KRd})(2 \%$ and $3 \%)[51]$.

+ Serum M protein (absolute increase $\geq 0.5 \mathrm{~g} / \mathrm{dL}$ ). Increased serum M protein $\geq 1 \mathrm{~g} / \mathrm{dL}$ indicates disease progression if the lowest serum $M$ component is $\geq 5 \mathrm{~g} / \mathrm{dL}$

+ Urine M protein (absolute increase $\geq 200 \mathrm{mg} / 24$ hours)

+ Percentage of bone marrow plasma cells (at least $10 \%$ absolute increase) in patients without measurable $M$ protein in serum or urine

+ Difference between kappa and lambda free light chain (FLC) levels (FLC ratio should be abnormal and absolute change should be $>10 \mathrm{mg} / \mathrm{dL}$ ). This FLC criterion should be used only for patients whose serum and urine protein $\mathrm{M}$ cannot be measured

- Identification of new lesions in bone or soft tissue (e.g., plasmacytomas) or unequivocal increase in previously existing lesion size

- Unexplained serum calcium $>11.5 \mathrm{mg} / \mathrm{dL}$ is also a marker of disease progression Refractory myeloma

Disease that does not respond during therapy or progresses within 60 days from the last therapy

- Relapsed and refractory myeloma (RRMM): disease that does not respond during rescue therapy or progresses within 60 days after the last therapy in patients who achieved a minimal or better previous response

- Primary refractory myeloma: refractory disease in patients who have never achieved a minor response with any relapsed myeloma therapy

Relapsed myeloma

Previously treated myelomas that, after a period with no treatment, require rescue therapy without the criteria for the "primary refractory" or "RRMM" categories
}

Figure 1: Definitions $[11,85]$. 
Table 3: Hematological toxicity and peripheral neuropathy with rescue protocols

\begin{tabular}{|c|c|c|c|c|c|c|c|c|c|}
\hline \multirow{2}{*}{$\begin{array}{l}\text { Adverse events (AEs) } \\
\text { Toxicity }\end{array}$} & \multicolumn{2}{|c|}{ Anemia } & \multicolumn{2}{|c|}{ Neutropenia } & \multicolumn{2}{|c|}{ Thrombocytopenia } & \multicolumn{2}{|c|}{ Peripheral neuropathy } & \multirow{2}{*}{$\begin{array}{c}\text { Second primary neoplasm } \\
-\end{array}$} \\
\hline & All & $\mathrm{G} 3 / 4$ & All & $\mathrm{G} 3 / 4$ & All & $\mathrm{G} 3 / 4$ & G0-5 (\%) & $\geq \mathrm{G} 3(\%)$ & \\
\hline POLLUX daratumumab arm* $[11,12,23,25]$ & 37 & 16 & 61 & 54 & 29 & 14 & NR & NR & 5.7 \\
\hline ASPIRE carfilzomib arm ${ }^{\#}[26-30]$ & 43 & 19 & 40 & 31 & 29 & 17 & 19 & 3 & NR \\
\hline ELOQUENT 2 elotuzumab arm ${ }^{\&}[13,14,31]$ & 97 & 20 & 83 & 36 & 84 & 21 & NR & NR & $*$ \\
\hline TOURMALINE-MM 1 ixazomib arm" [15] & 29 & 9 & 33 & 23 & 31 & 19 & 27 & 2 & 5 \\
\hline CASTOR daratumumab arm* $[11,16-18]$ & 26 & 14 & 18 & 13 & 59 & 45 & 50 & 5 & 4.1 \\
\hline ENDEAVOR carfilzomib arm $\operatorname{arm}^{\#}[19,20,30]$ & 40 & 15 & NR & NR & 21 & 9 & 10 & 1 & NR \\
\hline OPTIMISMM pomalidomide arm [21] & 28 & 13.7 & 46.8 & 82.1 & 36.7 & 27.3 & 47.8 & 8.3 & 3 \\
\hline PANORAMA1 panobinostat arm [22] & 62 & 18 & 75 & 35 & 98 & 68 & 61 & 18 & NR \\
\hline Lenalidomide, dexamethasone (POLLUX) $[11,12,17,25]$ & $39^{*}$ & 21 & 45 & 40 & 31 & 16 & $17-22$ & 3 & $3.6-5.7$ \\
\hline Lenalidomide, dexamethasone (ASPIRE) [26-30] & $40^{\#}$ & 18 & 35 & 28 & 24 & 13 & & & \\
\hline Lenalidomide, dexamethasone (ELOQUENT-2) $[13,14,31]$ & $95^{\&}$ & 21 & 89 & 45 & 78 & 21 & & & \\
\hline Lenalidomide, dexamethasone (TOURMALINE-MM1) [15] & $27^{\text {\#\# }}$ & 13 & 31 & 24 & 16 & 9 & & & \\
\hline Bortezomib, dexamethasone (Castor) [11, 16-18] & $31^{*}$ & 16 & 9 & 4 & 44 & 33 & 29-38 & 7 & 1 \\
\hline Bortezomib, dexamethasone (ENDEAVOR) [19, 20,30] & $28^{\# \#}$ & 11 & NR & NR & 17 & 9 & 29 & 6 & NR \\
\hline Bortezomib, dexamethasone (OPTIMISMM) [21] & 27 & 14 & 11 & 9 & 38 & 29 & 37 & 4 & 1 \\
\hline Bortezomib, dexamethasone (PANORAMA1) [22] & 52 & 19 & 48 & 8 & 84 & 31 & 67 & 15 & \\
\hline
\end{tabular}

* All degrees $(\geq 15 \%)$ and degree $3 / 4(\geq 5 \%) ;{ }^{*}(\geq 20 \%) ;{ }^{*}(\geq 30 \%) ;{ }^{*} \geq 10 \%$ and degree $3 / 4 / 5 \geq 2 \%$.

Discontinuation due to cardiovascular AEs was higher in patients aged $\geq 70$ years than in younger patients $(6.8 \%$ versus $1.4 \%$ ) [51]. When choosing a treatment, clinicians should consider cardiovascular toxicities (congestive heart failure and myocardial ischemia), especially in elderly or frail patients or those with previous heart disease. In these cases, physicians may opt for a non-carfilzomib regimen, as carfilzomib maybe results in a congestive heart failure rate of up to $5 \%$, with a death rate of $<1 \%[19,26]$.

Patients with known asthma and chronic obstructive pulmonary disease (COPD), with forced expiratory volume $<50 \%$ or moderate or serious persistent asthma in the last two years, should be carefully evaluated before receiving daratumumab due to the risk of bronchospasm; therefore, any patient with a history of COPD should be evaluated for concurrent use of short- and long-term bronchodilators and inhaled corticosteroids. Patients with mild asthma should take inhaled bronchodilators for the first infusion [59]. Discontinuation due to infusion-related reactions is rare $(<1 \%)[59]$.

\section{Cytogenetic abnormalities and type of relapse}

Patients with high-risk cytogenetics abnormalities (del17p, $t[4,14]$ and $t[14,16])$ have worse outcomes than those with typical cytogenetics. T $(4 ; 14)$ occurs in $11 \%$ and $8 \%$ of patients aged $66-75$ and $>75$ years, respectively, while del17p is observed in $6 \%$ of both age groups [60].

Regarding cytogenetics abnormalities, consideration should be given to choosing treatments that improve or overcome the poor prognosis of the disease (Supplementary Table 2). According to IMWG guidelines, patients with cytogenetics abnormalities should be rescued with regimens that combine proteasome inhibitors and immunomodulatory drugs [61]. In TOURMALINE-MM1, IRd was able to overcome the negative impact of high-risk cytogenetic abnormalities (PFS 21.4 months IRd versus 9.7 months in Rd, $p=0.021$ ) (Supplementary Table 2) [15]. Therefore, IRd may be an oral option for elderly patients.

In the case of biochemical relapse, especially during maintenance therapy, increasing the current drug dose and subsequently adding another agent is a recommended strategy [45]. In aggressive relapses with fast-growing tumors, new bone lesions, extramedullary disease, cytogenetics abnormalities, high lactate dehydrogenase levels and plasma cell leukemia, more aggressive therapy should be instituted with three- or four-drug regimens [7], while frail or elderly patients may be candidates for oral and well-tolerated regimens. In general, the regimens in Table 1 may be suitable for both situations.

\section{Response duration and previous treatment}

Elderly MM patients have a persistently worse prognosis than younger patients, which may be related to the higher frequency of treatment discontinuation and AEs [35]. In addition, elderly and frail patients are included in clinical trials less often than younger, healthier patients and therefore, may have less access to new drugs. There are also comorbidities and drug interactions that can complicate treatment, limit physical condition and impair adherence.

Repeating the same treatment is an option for patients with a lasting response, i.e., > 20-24 months after the first induction or > 9-12 months after rescue therapy [45]. Lower response duration should be treated with an alternative regimen. Patients who relapse $<12$ months after the first line or while undergoing treatment (refractory disease) should be treated as high risk regardless of their fluorescence in situ hybridization results [62]. 
In general, a second course of auto-SCT is not recommended in patients who relapse in $<12-18$ months (without maintenance) and $<36$ months (with lenalidomide maintenance), as the second course of autoSCT is likely to have an even smaller benefit than the first in terms of PFS [63].

On ERd, patients with a mean diagnosis time $\geq 3.5$ years had an advantage in PFS compared to those taking Rd (HR 0.59, CI: 0.45-0.78); the greatest benefit was observed in the subset with mean diagnosis time $\geq 3.5$ years and one previous line (30.4 versus 19.4 months, $p=$ 0.0224 ), with a $44 \%$ reduction in the risk of progression or death [14].

DRd versus Rd PFS benefits were maintained at prior treatment exposure time since last therapy $>$ 12 months (not applicable (NA) versus 25 months, $p<$ $0.0001), \leq 12$ months (29 versus 10 months, $p<0.0001$ ), $>6$ months (NA versus 21 months, $p<0.0001$ ) and $\leq 6$ months (NA versus 10 months, $p=0.0002$ ) [25].

The benefit in PFS with DVd versus Vd was maintained regardless of the time since last therapy $(\leq 12$, $>12, \leq 6$ or $>6$ months: 10 versus 5 months, NA versus 9.4 months, 10 versus 5 months and 20 versus 9 months, respectively) [18].

The treatment suggested for RRMM is described in Figure 5 and is based on type and sensitivity to the previous therapy, duration of response and available drugs (Supplementary Table 3). DRd and KRd improved PFS in patients with 1 or 2-3 previous lines - the same for DVd and $\mathrm{Kd}$. For IRd and ERd, the greatest benefit in PFS occurred in patients with $2-3$ previous lines. In real life, $61 \%$ start a second line $(10 \%$ disease progression, $4 \%$ patient refusal and $1 \%$ toxicity), 38\% start a third line ( $16 \%$ disease progression, $6 \%$ refusal and $4 \%$ toxicity) and only $15 \%$ start a fourth line $(24 \%$ by disease progression, $8 \%$ refusal and $2 \%$ toxicity) [64].
Lifestyle: patient preferences, hospital visits, travel, infusion route and time

Suboptimal adherence or treatment interruption by the patient may be related to the low understanding or acceptance of treatment by the patient and have a negative impact on survival.

A strategy to humanize the medical prescription in our public service and make it clear to illiterate or difficultto-understand patients (mostly due to polypharmacy), is to place a colored sticker on each oral medication box or bottle, each color corresponding to a different drug. In parallel with the medical prescription, a drawing of the sun (which represents the morning), a plate with cutlery (which represents lunch) and a moon (which represents the night) is made, so that each colored ball (drug) is glued respectively in period that it must be taken.

None of the previous studies (Table 1) addressed patient preference with RRMM. Preferences may vary due to treatment availability, previous treatments, disease duration, lack of motivation due to treatment failures, AEs, and age. When considering rescue treatment, it is essential to review the patient's preferences and lifestyle $[7,65,66]$.

A study about German RRMM patients preferences with novel proteasome inhibitor-based combination treatments showed patients were more interested in the application mode of the therapy, followed by higher efficacy compared with safety. "Therapy application regimen" was assigned the highest importance for treatment decisions $(38.8 \%)$, followed by "time without progression of disease" (38.7\%), "possibility of AE heart failure" (13.9\%) and "possibility of AEs affecting the blood" (8.6\%). Patients preferred oral intake once a day and once a week over other application modes and the highest overall utility was derived for IRd (utility: 3.218 ), compared with Rd (2.769), and KRd (1.928) [67].

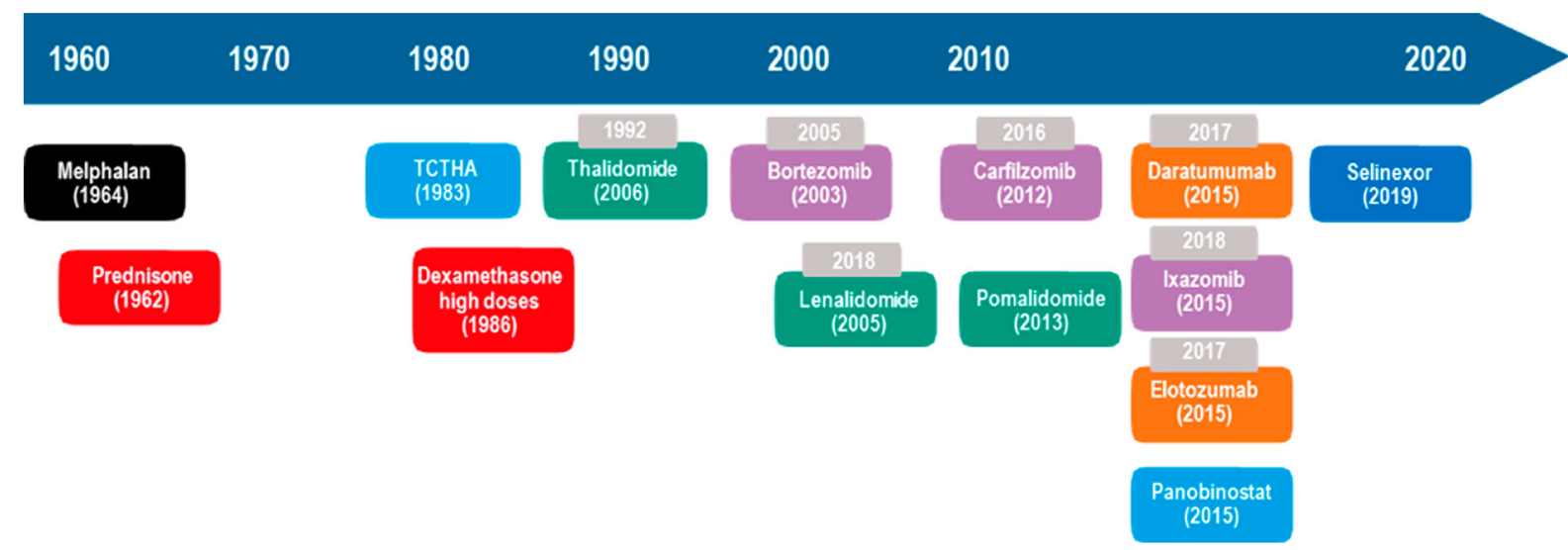

Figure 2: Evolution of MM treatment in the US. Gray = year of approval in Brazil. Black= alkylating agents. Red = corticosteroids. Green $=$ immunomodulators. Purple $=$ proteasome inhibitors. Orange $=$ monoclonal antibodies. Blue $=$ histone deacetylase inhibitor. auto$\mathrm{SCT}=$ autologous hematopoietic stem cell transplantation. Dark blue $=$ selective inhibitor of the nuclear export protein exportin $1(\mathrm{XPO})$. Oral or intravenous drugs: melphalan and dexamethasone. Oral drugs only: prednisone, thalidomide, lenalidomide, pomalidomide, ixazomib, panabinostat and selinexor. Intravenous only: Carfilzomib and elotozumab. Intravenous or subcutaneous: bortezomibe and daratumumab. 
A study used TSQM-9 (a general measure of patients' satisfaction with medication) to investigate satisfaction with current treatment in patients with NDMM and showed that oral administration route of current therapy was a predictor of higher patient-perceived convenience while the use of therapies containing an injectable agent was associated with increased activity impairment (more work time missed and impairment while working), increased time burden, and higher indirect costs (\$US482 versus 153) of MM therapy for patients and caregivers compared with solely orally administered therapies [68]. Similar data were observed for RRMM patients. 'Chari et al. Tx Satisfaction in RRMM. The Oncologist. 2019. Another study reported that patients with MM using an oral-only regimen reported fewer clinic visits in the past 3 months, lower out-of-pocket costs for these visits, and less time spent at appointments related to MM treatments in the past month than did those receiving an injectable regimen [69].
Oral drugs may be preferable for patients who want to travel or live far from the reference center, as they reduce visits to the clinic. For example, the number of visits in 18 cycles is 18 for Rd, 18 for IRd, 28 for DRd, 96 for KRd (biweekly) and 48 for KRd (weekly) [15, 25, 26, 70].

Some patients refuse lenalidomide, fearing a second primary neoplasm (Table 3 ) [11, 12, 17, 25], and choose a non-lenalidomide regimen (DVd or $\mathrm{Kd}$ ) instead. In our experience, others accept treatment but skip doses to be less exposed. Some prefer not to apply for health insurance coverage of lenalidomide (not yet on the list) and opt for DVd or $\mathrm{Kd}$.

Continuous oral thalidomide is rarely used for RRMM, as it is generally been used as only one component of a multidrug first-line treatment (cyclophosphamide, thalidomide and dexamethasone; bortezomib, thalidomide and dexamethasone; melphalan, prednisone and thalidomide) and has specific intolerable AEs (PN, constipation or bradycardia) in some cases [48, 49, 52, 54].

\section{Relevant factors in choosing an RRMM treatment}

1. Frailty: age, performance status, disabilities, comorbidities

2. Morbidity: refractory disease, renal failure, bone disease

3. Risk stratification (high risk or standard risk disease): cytogenetic abnormalities

4. Type of relapse: indolent/biochemical versus aggressive

5. Previous treatments: number and type of previous lines; for example, some studies have excluded patients refractory to lenalidomide

\section{Duration of response to these treatments}

7. Toxicity/comorbidity profile

a) Renal impairment: carfilzomib/ixazomib/elotuzumab/daratumumab and lenalidomide may be used

b) Consider variable adverse events with combination therapies: cardiovascular toxicity/severe COPD/skin sensitivity etc.

\section{Prior adverse events}

9. Lifestyle: patient preferences/hospital visits/travel/infusion time

\section{Access to new drugs}

\section{Oral chemotherapy advantages}

1. Improved quality of life: simple, fast and painless

2. Greater convenience: no need to travel to a health service at every dose and less impairment of daily activities such as work, family life, and frequent hospital visits/appointments

3. Time saving: intravenous (IV) infusions (take hours) versus taking pills (takes minutes).

Figure 3: Relevant factors in the therapeutic choice and oral chemotherapy [7]. 


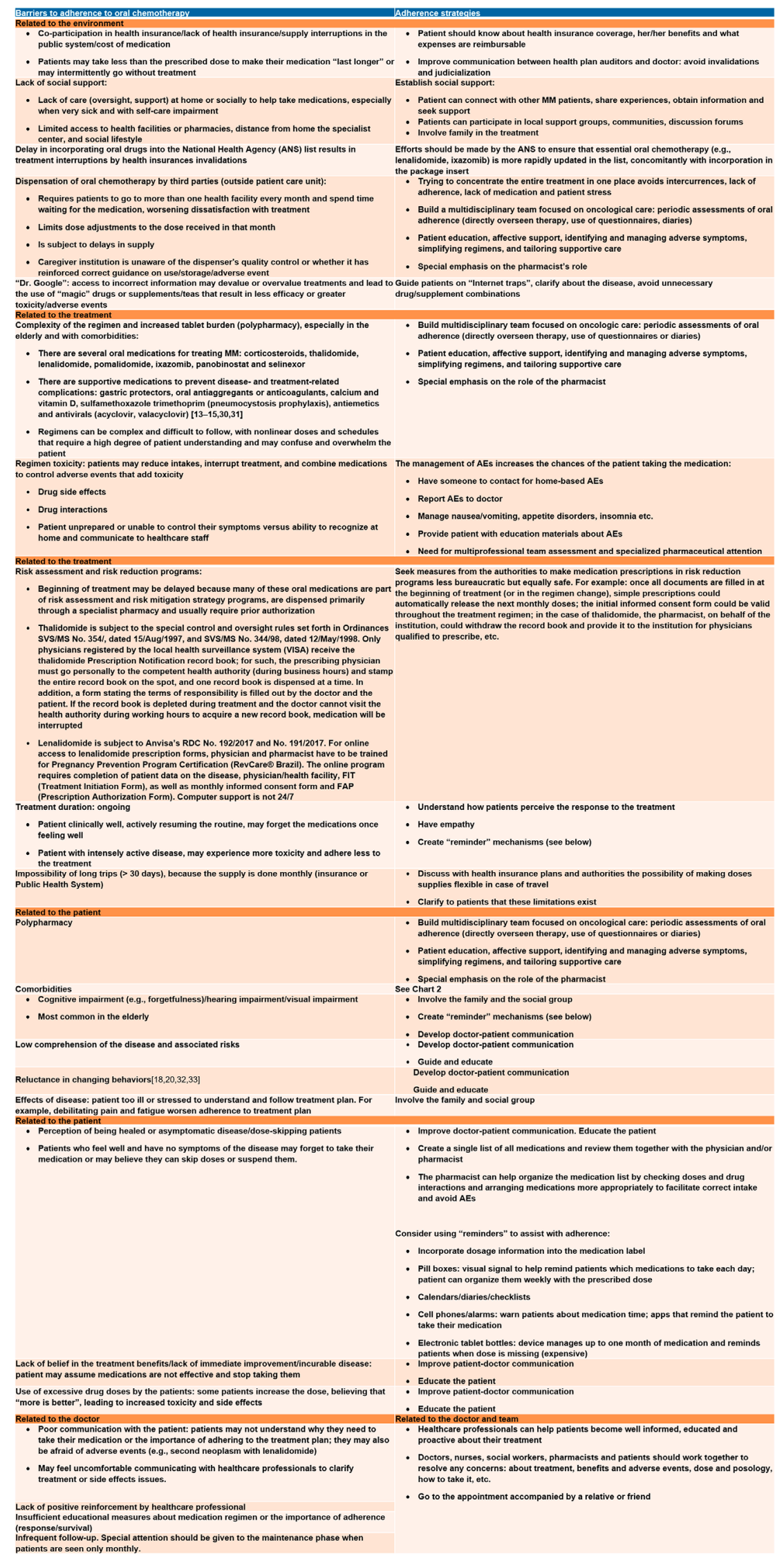

Figure 4: Barriers to adherence and strategies for adherence to oral chemotherapy $[65,66]$. Some items in the table are based on our experience. 
Lenalidomide $(5 \mathrm{mg}, 10 \mathrm{mg}, 15 \mathrm{mg}$ and $25 \mathrm{mg}$ capsules) may be used in regimens ranging from 14 to 21 days or continuously; taken at the same time, it contains lactose and, due to thrombotic risk, should be associated with acetylsalicylic acid or anticoagulants (if high risk) [40].

Pomalidomide $(1 \mathrm{mg}, 2 \mathrm{mg}, 3 \mathrm{mg}$ and $4 \mathrm{mg}$ capsules), another immunomodulatory and antiangiogenic drug, is lactose free and is taken orally at $4 \mathrm{mg} /$ day on days 1-14 (of a 21-day cycle) or 1-21 (of a 28-day cycle). The most common grade 3-4 adverse event associated with pomalidomide plus low-dose dexamethasone is myelosuppression. Aspirin prophylaxis is generally recommended for patients with a standard risk of venous thromboembolism, and low-molecular-weight heparin (prophylactic dose) or vitamin $\mathrm{K}$ antagonists (international normalized ratio 2-3) are recommended for patients with a high risk of venous thromboembolism [24, 43].

Ixazomib, the first oral proteasome inhibitor (2.3 $\mathrm{mg}, 3 \mathrm{mg}$ or $4 \mathrm{mg}$ capsule), has a weekly dosage (D1, D8 and D15), with rest in the last week of the 28-day cycle; this drug, taken at least one hour before or two hours after food, does not contain lactose. Antivirals should be considered for herpes zoster prevention [41].

Currently, bortezomib is preferentially given subcutaneously once a week, which causes fewer AEs than biweekly intravenous administration, reducing patient time in the hospital $[57,58]$. Bortezomib may produce allergic reactions at the application site but is usually well tolerated [42]. Intravenous carfilzomib, $60 \mathrm{mg} / \mathrm{vial}$, was previously applied twice a week (a reason for refusal by several patients), implying two weekly hospital visits for two consecutive days - a disadvantage compared to daratumumab which is administered weekly. Recently, the A.R.R.O.W. study [70] demonstrated similar results between biweekly and weekly dosages (with the dose increased to $70 \mathrm{mg} / \mathrm{m}^{2}$ ) for the $\mathrm{Kd}$ regimen, with fewer hospital visits positively impacting quality of life. Some patients using carfilzomib due to infusion-associated phlebitis require a long-term venous catheter (port-a-cath or peripherally inserted central venous catheter), a factor that may also impact treatment choice and quality of life. Doses of $20 / 27 \mathrm{mg} / \mathrm{m}^{2}$ are given within 10 minutes and $20 / 56 / 70 \mathrm{mg} / \mathrm{m}^{2}$ within 30 minutes, an advantage over daratumumab. The median PFS was increased in the weekly Kd group (11.2 months versus 7.6 months, $p=$ 0.0029 ), and the incidence of grade $\geq 3$ AEs was also slightly increased ( $68 \%$ versus $62 \%$ ). A smaller proportion of patients had grade $\geq 3$ congestive heart failure in weekly versus biweekly $\mathrm{Kd}(3 \%$ versus $4 \%$ ) [70].

Regarding daratumumab, in addition to premedication, the infusion takes longer due to the incidence and seriousness of related infusion reactions with infusion times for the first, second and subsequent infusions of $6.5,4.5$ and 3.5 hours, respectively [71]. The addition of $10 \mathrm{mg}$ of montelukast as a premedication before the first daratumumab infusion reduced onethird of the related infusion reactions [72]. Overall, 48\% had related infusion reactions, 92\% (cough, dyspnea, vomiting) at first infusion (5.3\% G3), and one patient discontinued [23]. A study showed that increasing the infusion rate as of the third daratumumab infusion did not

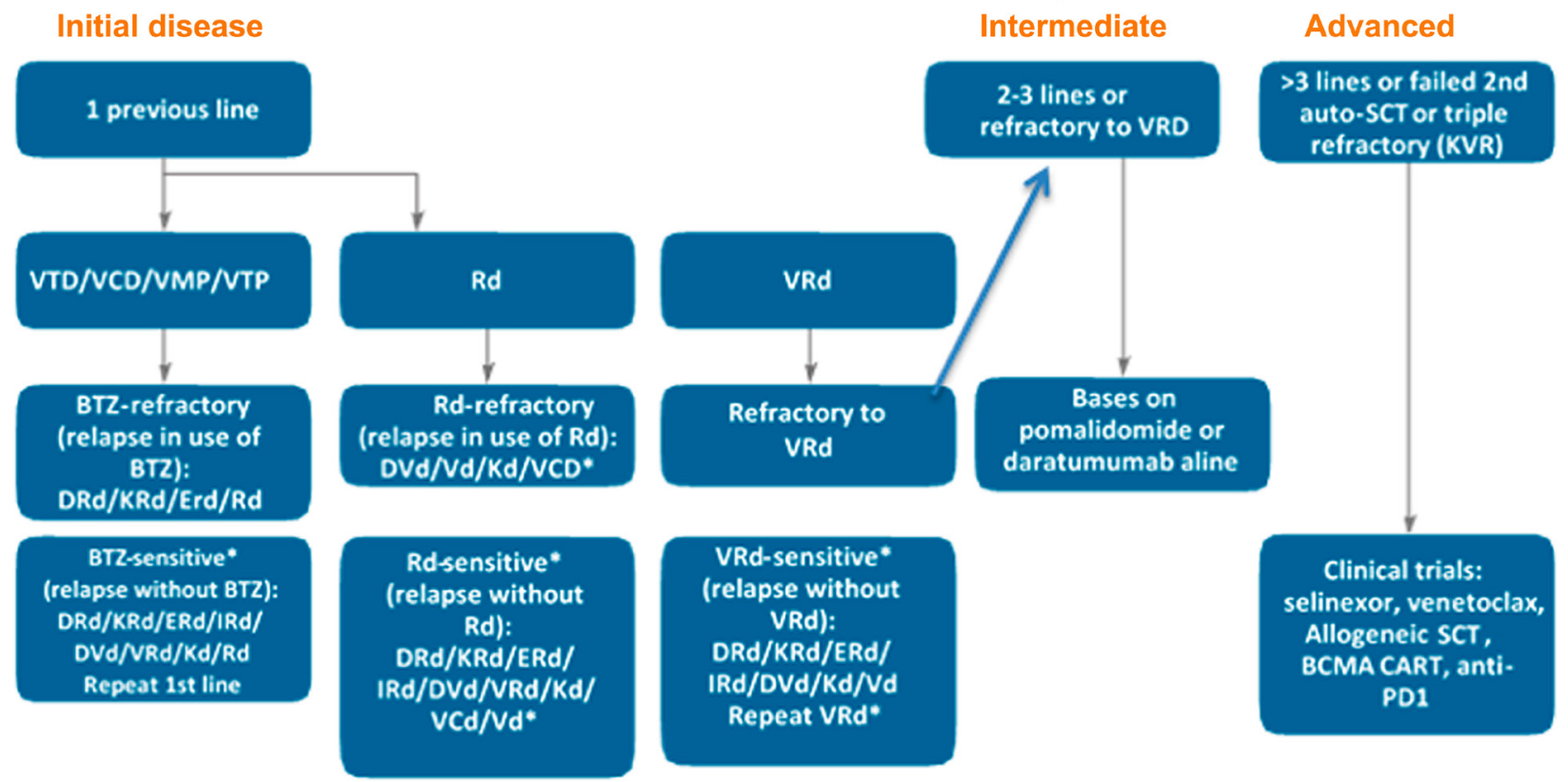

Figure 5: Proposed algorithm to treat early, intermediate and advanced disease (based on the number of previous lines). "In Brazil, pomalidomide is not available (PCd, KPd, DPd, VPd and Pd are alternative options). IRd and ERd have a significant effect on PFS in patients with second and third previous lines not refractory to lenalidomide and preferably sensitive to bortezomib [13-15, 31, 86]. Patients who relapse after $\geq 2$ years are considered sensitive. 
affect the safety profile [72]. The 90-minute infusion of daratumumab was well tolerated, and with this, patients gained two hours a day [72]. Subcutaneous formulation was approved for FDA recently based on findings from the phase 3 COLUMBA (MMY3012) study (COLUMBA; NCT03277105).

Elotuzumab (300 $\mathrm{mg}$ and $400 \mathrm{mg}$ vial) was started at the infusion rate of $0.5 \mathrm{~mL} / \mathrm{min}$ and progressively increased up to $5 \mathrm{~mL} / \mathrm{min}$ after $3-4$ cycles $(10 \mathrm{mg} / \mathrm{kg}, \sim 3$ $\mathrm{h}$ infusion). There are $10 \%$ related infusion reactions, with $70 \%$ in the first dose and $1 \%$ discontinuity [73].

Panobinostat (10 mg, $15 \mathrm{mg}$ and $20 \mathrm{mg}$ capsules) is a potent oral pan-deacetylase inhibitor for RRMM that has received between one and three previous treatment regimens. It is taken at a dose of $20 \mathrm{mg}$ once every other day for 3 doses each week during weeks 1 and 2 of a 21 day treatment cycle. Determine the Fridericia-corrected QT interval prior to the start of therapy and verify that it is $<450 \mathrm{msec}$ prior to panobinostat initiation once severe and fatal cardiac ischemic events, severe arrhythmias, and electrocardiogram changes have occurred in patients receiving panobinostat. Common grade 3-4 included thrombocytopenia (256 [67\%] in the panobinostat group vs 118 [31\%] in the placebo group), diarrhea (97 [26\%] vs 30 [8\%]), and PN (67 [18\%] vs 55 [15\%]) [22].

Selinexor (20 mg tablet) is an oral selective inhibitor of nuclear export compound that blocks exportin 1 and leads to activation of tumor suppressor proteins and inhibition of nuclear factor $\kappa \mathrm{B}$ with activity in triple-class refractory MM compounds. This drug is taken at $80 \mathrm{mg} /$ dose twice weekly on days 1 and 3 each week. Grade $\geq$ 3 common adverse reactions reported in at least $20 \%$ of patients included thrombocytopenia, anemia, neutropenia and hyponatremia [74].

Thus, DRd, KRd and ERd require venous access and prolonged hospital visits. On the other hand, oral drugs require the patient to remember to take the medication and use it on appropriate days, requiring the patient and family to have at least a minimum understanding of the dosage. Nausea and vomiting may further compromise efficacy and should be managed. In patients who cannot ingest drugs orally, these medications cannot be crushed or administered by probe, and subcutaneous or intravenous medication should be chosen.

In addition, drug doses should be adapted based on patient characteristics to avoid excessive toxicities leading to treatment discontinuation, negatively affecting survival or quality of life. Lenalidomide, pomalidomide and ixazomib adjust for kidney function; pomalidomide, ixazomib, bortezomib and carfilzomib adjust for liver function [44].

\section{Coronavirus disease (COVID-19) outbreak}

On April 26, 2020, the pandemic of the new coronavirus (SARS-CoV2 / COVID-19), which appeared in December 2019 in the city of Wuhan, China, had already affected 213 countries, with 2,883,603 confirmed cases and 198,842 confirmed deaths in the world (WHO, 2020). There are concerns that the COVID-19 could overwhelm health-care systems worldwide, as severe and critical disease were reported, respectively, in 14 and 5 percent of patients, since they require intensive care assistance [75]. Most of the fatal cases occurred in patients with advanced age or underlying medical comorbidities $[75,76]$. China reported a case-fatality rate of $14.8 \%$ in patients aged $\geq$ 80 years (208 of 1408) and 8.0\% in patients aged 70-79 years (312 of 3918) [75]. Italian data reported that $20 \%$ of those who died from COVID-19 in the country had active cancer [77]. Patients with MM could be at particular risk from COVID-19, since they tend to be older, have multiple comorbidities as previously discussed, and they are immunosuppressed by their disease or therapy.

In such situation, caregivers should minimize their patients' exposure to health-care facilities and many groups are issuing guidance. ESMO recommended oncologists to adjust their routines and suggested bolstering telemedicine services, reducing clinic visits, and switching to subcutaneous or oral therapies, rather than intravenous ones, whenever possible [78]. EBMT recommended that non-urgent transplants should be deferred as much as possible [79].

For patients with MM, treatment can be individualized to limit additional exposure to COVID-19. According to the American Society of Hematology, a reasonable approach is starting triplet therapy with VRd for 6-12 cycles followed by lenalidomide maintenance in patients requiring treatment, and bortezomib can be added to this every 2 weeks for high-risk patients. Postponing the stem cell transplant (including hematopoietic stem and progenitor cells collection and storage) is recommended [80]. $\mathrm{Rd}$ is a rational choice for frail patients or after achieving best response. Maintenance therapy should go on, since the risk of myeloma relapse is higher without treatment, but if a patient gets COVID-19, treatment should be interrupted until infection resolution. In order to decrease clinic visits, strategies such as telemedicine check-ins, in-home blood draws as required and prescription delivery via mail should be advised [80].

A recent publication of Sorbonne University recommended during pandemic of COVID-19 to complete six cycles of induction regimens in all patients with $\mathrm{MM}$ to postpone the transplant procedure. Additional cycles of induction until first relapse should be considered in standard-risk MM; however, for high-risk cytogenetics (especially those with deletion of chromosome 17p) it was recommended to follow with auto-SCT as first-line treatments whenever possible. They encouraged reduction (as for elderly patients) or interruption of steroids in patients in complete remission, change the treatment administration schedule to one with a lower frequency, change daratumumab to every 4 weeks instead of every 2 weeks after the initial 8-week weekly administration, in 
patients with very good partial response; and switch from an intravenous or subcutaneous treatment to a fully oral treatment combination [81].

For bisphosphonate intravenous home administration, switch from an intravenous to an oral bisphosphonate, switch to zometa every 3 months or transient interruption are supported [80].

For RRMM patients oral salvage chemotherapy with IRd may be a reasonable option to reduce COVID-19 exposure.

\section{CONCLUSIONS}

Of the ten new antimyeloma drugs, seven are oral, simplifying intake and increasing patients' autonomy and quality of life, but these drugs also reduce the number of hospital visits and transfer the responsibility of treatment management to the patient. The best treatment may not work if the patient is unable to accomplish it, whether due to forgetfulness, AEs or lack of social support. Completely oral rescue protocols such as IRd are options for patients who do are unwilling or unable to go to the hospital every week, providing the benefits of triple therapies (including proteasome inhibitors and immunomodulatory drugs) against progression without increasing the burden on hospital resources. Treatment with oral chemotherapy is of special value during the COVID-19 outbreak. In clinical practice, choosing the optimal combination for each patient is a challenge. Relapse treatment is influenced by previous treatment lines, efficacy and safety, convenience, quality of life, preferences, and personal feelings, among others, and should be considered and discussed with each patient. It is essential to individualize the approach of elderly MM patients, recognizing logistical, perceptual, physiological and socioeconomic barriers that compromise adherence and, thus, treatment efficiency. "Intake reminder methods" such as alarms, diaries, applications, and "pill boxes" are effective; however, patient education and communication with healthcare professionals are critical for adherence.

\section{Abbreviations}

AEs: adverse events; auto-SCT: autologous hematopoietic stem cell transplantation; PVd: pomalidomide, bortezomib, and dexamethasone; $\mathrm{CrCl}$ : creatinine clearance; COPD: chronic obstructive pulmonary disease; DRd daratumumab, lenalidomide, and dexamethasone; DVd: daratumumab, bortezomib, and dexamethasone; ECOG: Eastern Cooperative Oncology Group performance status; ERd: elotuzumab, lenalidomide, and dexamethasone; IMWG: The International Myeloma Working Group; IRd: ixazomib, lenalidomide, and dexamethasone; $\mathrm{Kd}$ : carfilzomib and dexamethasone; KRd: carfilzomib, lenalidomide, and dexamethasone; MM: Multiple myeloma; NDMM: newly diagnosed multiple myeloma; RRMM: relapsed and/or refractory multiple myeloma; OS: overall survival; PFS: progression-free survival; PN: peripheral neuropathy; Pan-Vd: panobinostat, bortezomib, and dexamethasone; $\mathrm{Rd}$ : lenalidomide and dexamethasone; Vd: bortezomib and dexamethasone; VMP: bortezomib, melphalan and prednisone.

\section{ACKNOWLEDGMENTS}

Medical writing support was provided by Marion Coting of IQVIA, funded by Takeda.

\section{CONFLICTS OF INTEREST}

Flávia Dias Xavier has received fees for serving as an advisory board member for Amgen and Janssen, for serving as a speaker for Janssen, Amgen and Takeda and for preparing medical presentations for Takeda. Rodrigo Martins Abreu is Scientific Medical Manager in Medical Affairs at Takeda Distribuidora Ltd, Brazil. Fernando Sergio Blumm Ferreira report no conflicts of interest in this work.

\section{REFERENCES}

1. Howlader N, Noone A, Krapcho M, Miller D, Bishop K, Kosary C, Yu M, Ruhl J, Tatalovich Z, Mariotto A, Lewis D, Chen H, Feuer E, et al. SEER Cancer Statistics Review (CSR), 1975-2014. Natl Cancer Inst. 2017. https://seer. cancer.gov/csr/1975_2014/.

2. Palumbo A, Anderson K. Multiple myeloma. N Engl J Med. 2011; 364:1046-1060. https://doi.org/10.1056/ NEJMra1011442. [PubMed]

3. IBGE. IBGE | Projeção da população. Instituto Brasileiro de Geografia e Estatistica. 2013. https://www.ibge.gov.br/apps/ populacao/projecao/index.html.

4. United Nations. World population prospects: The 2015 Revision, Key Findings and Advance Tables. United Nations. 2015. https://population.un.org/wpp/Publications/ Files/Key_Findings_WPP 2015.pdf.

5. Reis C, Barbosa L. Maria de Lima Horta Pimentel VP. O desafio do envelhecimento populacional na perspectiva sistêmica da saúde. Banco Nac Desenvolv Econômico e Soc. 2016; 44:87-124. https://web.bndes.gov.br/bib/jspui/ bitstream/1408/9955/2/BS\%2044\%200\%20desafio $\% 20$ do $\% 20$ envelhecimento $\% 20$ populacional $\% 20$ na $\% 20$ perspectiva $\% 20$ sistemica $\% 20 \mathrm{da} \% 20$ saude_P.pdf.

6. Smith BD, Smith GL, Hurria A, Hortobagyi GN, Buchholz TA. Future of cancer incidence in the United States: Burdens upon an aging, changing nation. J Clin Oncol. 2009; 27:2758-2765. https://doi.org/10.1200/ JCO.2008.20.8983. [PubMed]

7. Sonneveld P, Broijl A. Treatment of relapsed and refractory multiple myeloma. Haematologica. 2016; 101:396-406. https://doi.org/10.3324/haematol.2015.129189. [PubMed] 
8. Kumar SK, Dispenzieri A, Lacy MQ, Gertz MA, Buadi FK, Pandey S, Kapoor P, Dingli D, Hayman SR, Leung N, Lust J, McCurdy A, Russell SJ, et al. Continued improvement in survival in multiple myeloma: Changes in early mortality and outcomes in older patients. Leukemia. 2014; 28:11228. https://doi.org/10.1038/leu.2013.313. [PubMed]

9. Thorsteinsdottir S, Dickman PW, Landgren O, Blimark C, Hultcrantz M, Turesson I, Björkholm M, Kristinsson SY. Dramatically improved survival in multiple myeloma patients in the recent decade: Results from a Swedish populationbased study. Haematologica. 2018; 103:e412-e415. https:// doi.org/10.3324/haematol.2017.183475. [PubMed]

10. Kristinsson SY, Anderson WF, Landgren O. Improved longterm survival in multiple myeloma up to the age of 80 years. Leukemia. 2014; 28:1346-1348. https://doi.org/10.1038/ leu.2014.23. [PubMed]

11. Rajkumar SV, Harousseau JL, Durie B, Anderson KC, Dimopoulos M, Kyle R, Blade J, Richardson P, Orlowski R, Siegel D, Jagannath S, Facon T, Avet-Loiseau H, et al, and International Myeloma Workshop Consensus Panel 1. Consensus recommendations for the uniform reporting of clinical trials: Report of the International Myeloma Workshop Consensus Panel 1. Blood. 2011; 117:4691-5. https://doi.org/10.1182/blood-2010-10-299487. [PubMed]

12. Avet-Loiseau H, Casneuf T, Chiu C, Laubach JP, Lee JJ, Moreau P, Plesner T, Nahi H, Khokhar NZ, Qi M, Schecter J, Carlton V, Qin X, et al. Evaluation of Minimal Residual Disease (MRD) in Relapsed/Refractory Multiple Myeloma (RRMM) Patients Treated with Daratumumab in Combination with Lenalidomide Plus Dexamethasone or Bortezomib Plus Dexamethasone. Blood. 2016; 128:246246. https://doi.org/10.1182/blood.V128.22.246.246.

13. Dimopoulos MA, Lonial S, White D, Moreau P, Palumbo A, San-Miguel J, Shpilberg O, Anderson K, Grosicki S, Spicka I, Walter-Croneck A, Magen H, Mateos MV, et al. Elotuzumab plus lenalidomide/dexamethasone for relapsed or refractory multiple myeloma: ELOQUENT-2 followup and post-hoc analyses on progression-free survival and tumour growth. Br J Haematol. 2017; 178:896-905. https:// doi.org/10.1111/bjh.14787. [PubMed]

14. Dimopoulos MA, Lonial S, Betts KA, Chen C, Zichlin ML, Brun A, Signorovitch JE, Makenbaeva D, Mekan S, Sy O, Weisel K, Richardson PG. Elotuzumab plus lenalidomide and dexamethasone in relapsed/refractory multiple myeloma: Extended 4-year follow-up and analysis of relative progression-free survival from the randomized ELOQUENT-2 trial. Cancer. 2018; 124:4032-4043. https:// doi.org/10.1002/cncr.31680. [PubMed]

15. Moreau P, Masszi T, Grzasko N, Bahlis NJ, Hansson M, Pour L, Sandhu I, Ganly P, Baker BW, Jackson SR, Stoppa AM, Simpson DR, Gimsing P, et al, and TOURMALINEMM1 Study Group. Oral Ixazomib, lenalidomide, and dexamethasone for multiple myeloma. N Engl J Med. 2016; 374:1621-1634. https://doi.org/10.1056/NEJMoa1516282. [PubMed]
16. Palumbo A, Chanan-Khan A, Weisel K, Nooka AK, Masszi T, Beksac M, Spicka I, Hungria V, Munder M, Mateos MV, Mark TM, Qi M, Schecter J, et al, and CASTOR Investigators. Daratumumab, bortezomib, and dexamethasone for multiple myeloma. N Engl J Med. 2016; 375:754-766. https://doi.org/10.1056/NEJMoa1606038. [PubMed]

17. Weisel KC, San Miguel J, Cook G, Leiba M, Suzuki K, Kumar S, Cavo M, Avet-Loiseau H, Quach H, Hungria V, Lentzsch S, Hajek R, Sonneveld P, et al. Efficacy of daratumumab in combination with lenalidomide plus dexamethasone (DRd) or bortezomib plus dexamethasone (DVd) in relapsed or refractory multiple myeloma (RRMM) based on cytogenetic risk status. J Clin Oncol. 2017; 35:8006. https://doi.org/10.1200/JCO.2017.35.15 suppl.8006.

18. Spencer A, Lentzsch S, Weisel K, Avet-Loiseau H, Mark TM, Spicka I, Masszi T, Lauri B, Levin MD, Bosi A, Hungria V, Cavo M, Lee JJ, et al. Daratumumab plus bortezomib and dexamethasone versus bortezomib and dexamethasone in relapsed or refractory multiple myeloma: Updated analysis of CASTOR. Haematologica. 2018; 103:2079-2087. https://doi.org/10.3324/ haematol.2018.194118. [PubMed]

19. Dimopoulos MA, Moreau P, Palumbo A, Joshua D, Pour L, Hájek R, Facon T, Ludwig H, Oriol A, Goldschmidt H, Rosiñol L, Straub J, Suvorov A, et al, and ENDEAVOR Investigators. Carfilzomib and dexamethasone versus bortezomib and dexamethasone for patients with relapsed or refractory multiple myeloma (ENDEAVOR): a randomize, phase 3, open-label, multicentre study. Lancet Oncol. 2016; 17:27-38. https://doi.org/10.1016/S1470-2045(15)00464-7. [PubMed]

20. Dimopoulos MA, Goldschmidt H, Niesvizky R, Joshua D, Chng WJ, Oriol A, Orlowski RZ, Ludwig H, Facon T, Hajek R, Weisel K, Hungria V, Minuk L, et al. Carfilzomib or bortezomib in relapsed or refractory multiple myeloma (ENDEAVOR): an interim overall survival analysis of an open-label, randomised, phase 3 trial. Lancet Oncol. 2017; 18:1327-1337. https://doi.org/10.1016/S14702045(17)30578-8. [PubMed]

21. Richardson PG, Oriol A, Beksac M, Liberati AM, Galli M, Schjesvold F, Lindsay J, Weisel K, White D, Facon T, San Miguel J, Sunami K, O'Gorman P, et al, and OPTIMISMM trial investigators. Pomalidomide, bortezomib, and dexamethasone for patients with relapsed or refractory multiple myeloma previously treated with lenalidomide (OPTIMISMM): a randomised, open-label, phase 3 trial. Lancet Oncol. 2019; 20:781-794. https://doi.org/10.1016/ S1470-2045(19)30152-4. [PubMed]

22. San-Miguel JF, Hungria VTM, Yoon SS, Beksac M, Dimopoulos MA, Elghandour A, Jedrzejczak WW, Günther A, Nakorn TN, Siritanaratkul N, Corradini P, Chuncharunee S, Lee JJ, et al. Panobinostat plus bortezomib and dexamethasone versus placebo plus bortezomib and dexamethasone in patients with relapsed or relapsed and 
refractory multiple myeloma: a multicentre, randomised, double-blind phase 3 trial. Lancet Oncol. 2014; 15:11951206. https://doi.org/10.1016/S1470-2045(14)70440-1. [PubMed]

23. Dimopoulos MA, Oriol A, Nahi H, San-Miguel J, Bahlis NJ, Usmani SZ, Rabin N, Orlowski RZ, Komarnicki M, Suzuki K, Plesner T, Yoon SS, Ben Yehuda D, et al, and POLLUX Investigators. Daratumumab, lenalidomide, and dexamethasone for multiple myeloma. N Engl J Med. 2016; 375:1319-1331. https://doi.org/10.1056/NEJMoa1607751. [PubMed]

24. Dimopoulos MA, Leleu X, Palumbo A, Moreau P, Delforge M, Cavo M, Ludwig H, Morgan GJ, Davies FE, Sonneveld P, Schey SA, Zweegman S, Hansson M, et al. Expert panel consensus statement on the optimal use of pomalidomide in relapsed and refractory multiple myeloma. Leukemia. 2014; 28:1573-1585. https://doi.org/10.1038/leu.2014.60. [PubMed]

25. Dimopoulos MA, San-Miguel J, Belch A, White D, Benboubker L, Cook G, Leiba M, Morton J, Ho PJ, Kim K, Takezako N, Moreau P, Kaufman JL, et al. Daratumumab plus lenalidomide and dexamethasone versus lenalidomide and dexamethasone in relapsed or refractory multiple myeloma: updated analysis of POLLUX. Haematologica. 2018; 103:2088-2096. https://doi. org/10.3324/haematol.2018.194282. [PubMed]

26. Stewart AK, Rajkumar SV, Dimopoulos MA, Masszi T, Špicka I, Oriol A, Hajek R, Rosinol L, Siegel DS, Mihaylov GG, Goranova-Marinova V, Rajnics P, Suvorov A, et al, and ASPIRE Investigators. Carfilzomib, lenalidomide, and dexamethasone for relapsed multiple myeloma. N Engl J Med. 2015; 372:142-152. https://doi.org/10.1056/ NEJMoa1411321. [PubMed]

27. Avet-Loiseau H, Fonseca R, Siegel D, Dimopoulos MA, Špička I, Masszi T, Hájek R, Rosiñol L, GoranovaMarinova V, Mihaylov G, Maisnar V, Mateos MV, Wang M, et al. Carfilzomib significantly improves the progressionfree survival of high-risk patients in multiple myeloma. Blood. 2016; 128:1174-1180. https://doi.org/10.1182/ blood-2016-03-707596. [PubMed]

28. Dimopoulos MA, Stewart AK, Masszi T, Špička I, Oriol A, Hájek R, Rosiñol L, Siegel D, Mihaylov GG, GoranovaMarinova V, Rajnics P, Suvorov A, Niesvizky R, et al. Carfilzomib, lenalidomide, and dexamethasone in patients with relapsed multiple myeloma categorised by age: secondary analysis from the phase 3 ASPIRE study. Br J Haematol. 2017; 177:404-413. https://doi.org/10.1111/ bjh.14549. [PubMed]

29. Siegel DS, Dimopoulos MA, Ludwig H, Facon T, Goldschmidt H, Jakubowiak A, San-Miguel J, Obreja M, Blaedel J, Stewart AK. Improvement in overall survival with carfilzomib, lenalidomide, and dexamethasone in patients with relapsed or refractory multiple myeloma. J Clin Oncol. 2018; 36:728-734. https://doi.org/10.1200/ JCO.2017.76.5032. [PubMed]
30. Siegel DS, Oriol A, Rajnics P, Minarik J, Hungria V, Lee JH, Song K, Obreja M, Aggarwal S, Hajek R. Updated Results from ASPIRE and ENDEAVOR, Randomized, Open-Label, Multicenter Phase 3 Studies of Carfilzomib in Patients (Pts) with Relapsed/Refractory Multiple Myeloma (RRMM). Clin Lymphoma Myeloma Leuk. 2017; 17:e142. https://doi.org/10.1016/j.clml.2017.03.256.

31. Lonial S, Dimopoulos M, Palumbo A, White D, Grosicki S, Spicka I, Walter-Croneck A, Moreau P, Mateos MV, Magen H, Belch A, Reece D, Beksac M, et al, and ELOQUENT-2 Investigators. Elotuzumab therapy for relapsed or refractory multiple myeloma. N Engl J Med. 2015; 373:621-631. https://doi.org/10.1056/NEJMoa1505654. [PubMed]

32. Zafar SY. Financial Toxicity of Cancer Care: It's Time to Intervene. J Natl Cancer Inst. 2015; 108:djv370. https://doi. org/10.1093/jnci/djv370. [PubMed]

33. Iuga AO, McGuire MJ. Adherence and health care costs. Risk Manag Healthc Policy. 2014; 7:35-44. https://doi. org/10.2147/RMHP.S19801. [PubMed]

34. Vander Stichele R. Measurement of patient compliance and the interpretation of randomized clinical trials. Eur $\mathrm{J}$ Clin Pharmacol. 1991; 41:27-35. https://doi.org/10.1007/ BF00280102. [PubMed]

35. Palumbo A, Bringhen S, Mateos MV, Larocca A, Facon T, Kumar SK, Offidani M, McCarthy P, Evangelista A, Lonial S, Zweegman S, Musto P, Terpos E, et al. Geriatric assessment predicts survival and toxicities in elderly myeloma patients: An International Myeloma Working Group report. Blood. 2015; 125:2068-2074. https://doi. org/10.1182/blood-2014-12-615187. [PubMed]

36. Richardson PG, Weller E, Lonial S, Jakubowiak AJ, Jagannath S, Raje NS, Avigan DE, Xie W, Ghobrial IM, Schlossman RL, Mazumder A, Munshi NC, Vesole DH, et al. Lenalidomide, bortezomib, and dexamethasone combination therapy in patients with newly diagnosed multiple myeloma. Blood. 2010; 116:679-86 . https://doi. org/10.1182/blood-2010-02-268862. [PubMed]

37. Dimopoulos MA, Sonneveld P, Leung N, Merlini G, Ludwig H, Kastritis E, Goldschmidt H, Joshua D, Orlowski RZ, Powles R, Vesole DH, Garderet L, Einsele H, et al. International Myeloma working group recommendations for the diagnosis and management of Myeloma-Related Renal Impairment. J Clin Oncol. 2016; 34:1544-1557. https://doi. org/10.1200/JCO.2015.65.0044. [PubMed]

38. Glassock RJ, Rule AD. The implications of anatomical and functional changes of the aging kidney: With an emphasis on the glomeruli. Kidney Int. 2012; 82:270-277. https://doi. org/10.1038/ki.2012.65. [PubMed]

39. Ebert N, Jakob O, Gaedeke J, Van Der Giet M, Kuhlmann MK, Martus P, Mielke N, Schuchardt M, Tölle M, Wenning $\mathrm{V}$, Schaeffner ES. Prevalence of reduced kidney function and albuminuria in older adults: The Berlin initiative study. Nephrol Dial Transplant. 2017; 32:997-1005. https://doi. org/10.1093/ndt/gfw079. [PubMed] 
40. Celgene Brasil Produtos Farmacêuticos, Ltda. Revlimid (Lenalidomide). Bula. 2019. https://media.celgene.com/ content/uploads/sites/19/Revlimid_Bula_Profissional.pdf.

41. Takeda Pharma Ltd. Ninlaro (Ixazomib). Bula. 2018. https:// www.takeda.com/4ab3a7/siteassets/pt-br/home/what-wedo/produtos/ni caps 12190120 vps.pdf.

42. Janssen-Cilag Farmacêutica, Ltda. Velcade (Bortezomib). Bula. 2018. https://www.janssen.com/brasil/sites/www janssen_com_brazil/files/prod_files/live/velcade_pub_vps. pdf.

43. Celgene Corporation. PRESCRIBING INFORMATION POMALYST $^{\circledR}$ (pomalidomide) capsules, for oral use. U.S. Food and Drug Administration. 2013. https://www. accessdata.fda.gov/drugsatfda docs/label/2013/2040261bl. pdf.

44. Lexicomp Online, Drug Information Handbook. Hudson, Ohio: UpToDate, Levothyroxine, 2015.

45. Palumbo A, Rajkumar SV, San Miguel JF, Larocca A, Niesvizky R, Morgan G, Landgren O, Hajek R, Einsele $\mathrm{H}$, Anderson KC, Dimopoulos MA, Richardson PG, Cavo $\mathrm{M}$, et al. International Myeloma Working Group consensus statement for the management, treatment, and supportive care of patients with myeloma not eligible for standard autologous stem-cell transplantation. J Clin Oncol. 2014; 32:587-600. https://doi.org/10.1200/JCO.2013.48.7934. [PubMed]

46. Novartis Pharmaceuticals Corporation. PRESCRIBING INFORMATION FARYDAK ${ }^{\circledR}$ (panobinostat) capsules, for oral use. U.S. Food and Drug Administration. 2015. https://www.accessdata.fda.gov/drugsatfda_docs/ label/2015/205353s000lbl.pdf.

47. Karyopharm Therapeutics Inc. PRESCRIBING INFORMATION XPOVIOTM (selinexor) tablets, for oral use. U.S. Food and Drug Administration. 2019. https://www.accessdata.fda.gov/drugsatfda_docs/ label/2019/212306s000lbl.pdf.

48. Kumar S, Giralt S, Stadtmauer EA, Harousseau JL, Palumbo A, Bensinger W, Comenzo RL, Lentzsch S, Munshi N, Niesvizky R, San Miguel J, Ludwig H, Bergsagel L, et al, and International Myeloma Working Group. Mobilization in myeloma revisited: IMWG consensus perspectives on stem cell collection following initial therapy with thalidomide-, lenalidomide-, or bortezomib-containing regimens. Blood. 2009; 114:1729-1735. https://doi.org/10.1182/ blood-2009-04-205013. [PubMed]

49. Mateos MV, Oriol A, Martínez-López J, Gutiérrez N, Teruel AI, de Paz R, García-Laraña J, Bengoechea E, Martín A, Mediavilla JD, Palomera L, de Arriba F, González Y, et al. Bortezomib, melphalan, and prednisone versus bortezomib, thalidomide, and prednisone as induction therapy followed by maintenance treatment with bortezomib and thalidomide versus bortezomib and prednisone in elderly patients with untreated multiple myeloma: a randomised trial. Lancet Oncol. 2010; 11:934-941. https://doi.org/10.1016/S14702045(10)70187-X. [PubMed]
50. Diamond E, Lahoud OB, Landau H. Managing multiple myeloma in elderly patients. Leuk Lymphoma. 2018; 59:1300-1311. https://doi.org/10.1080/10428194.2017.13 65859. [PubMed]

51. Chari A, Keith Stewart A, Russell SD, Moreau P, Herrmann J, Banchs J, Hajek R, Groarke J, Lyon AR, Batty GN, Ro S, Huang M, Iskander KS, Lenihan D. Analysis of carfilzomib cardiovascular safety profile across relapsed and/or refractory multiple myeloma clinical trials. Blood Adv. 2018; 2:1633-1644. https://doi.org/10.1182/ bloodadvances.2017015545. [PubMed]

52. Mileshkin L, Prince HM. The troublesome toxicity of peripheral neuropathy with thalidomide. Leuk Lymphoma. 2006; 47:2276-9. https://doi. org/10.1080/10428190600948303. [PubMed]

53. Richardson PG, Delforge M, Beksac M, Wen P, Jongen JL, Sezer O, Terpos E, Munshi N, Palumbo A, Rajkumar SV, Harousseau JL, Moreau P, Avet-Loiseau H, et al. Management of treatment-emergent peripheral neuropathy in multiple myeloma. Leukemia. 2012; 26:595-608. https:// doi.org/10.1038/leu.2011.346. [PubMed]

54. Facon T, Mary JY, Hulin C, Benboubker L, Attal M, Pegourie B, Renaud M, Harousseau JL, Guillerm G, Chaleteix C, Dib M, Voillat L, Maisonneuve H, et al, and Intergroupe Francophone du Myélome. Melphalan and prednisone plus thalidomide versus melphalan and prednisone alone or reduced-intensity autologous stem cell transplantation in elderly patients with multiple myeloma (IFM 99-06): a randomised trial. Lancet. 2007; 370:1209-1218. https://doi. org/10.1016/S0140-6736(07)61537-2. [PubMed]

55. Gay F, Palumbo A. Management of older patients with multiple myeloma. Blood Rev. 2011; 25:65-73. https://doi. org/10.1016/j.blre.2010.10.003. [PubMed]

56. Mateos MV, Dimopoulos MA, Cavo M, Suzuki K, Jakubowiak A, Knop S, Doyen C, Lucio P, Nagy Z, Kaplan P, Pour L, Cook M, Grosicki S, et al, and ALCYONE Trial Investigators. Daratumumab plus bortezomib, melphalan, and prednisone for untreated myeloma. N Engl J Med. 2018; 378:518-528. https://doi.org/10.1056/NEJMoa1714678. [PubMed]

57. Moreau P, Pylypenko H, Grosicki S, Karamanesht I, Leleu X, Grishunina M, Rekhtman G, Masliak Z, Robak T, Shubina A, Arnulf B, Kropff M, Cavet J, et al. Subcutaneous versus intravenous administration of bortezomib in patients with relapsed multiple myeloma: A randomised, phase 3, non-inferiority study. Lancet Oncol. 2011; 12:431-440. https://doi.org/10.1016/S1470-2045(11)70081-X. [PubMed]

58. Bringhen S, Larocca A, Rossi D, Cavalli M, Genuardi M, Ria R, Gentili S, Patriarca F, Nozzoli C, Levi A, Guglielmelli T, Benevolo G, Callea V, et al. Efficacy and safety of once-weekly bortezomib in multiple myeloma patients. Blood. 2010; 116:4745-53. https://doi. org/10.1182/blood-2010-07-294983. [PubMed]

59. Moreau P, van de Donk NW, San Miguel J, Lokhorst H, Nahi H, Ben-Yehuda D, Cavo M, Cook G, Delforge M, 
Einsele H, Zweegman S, Ludwig H, Driessen C, et al. Practical Considerations for the Use of Daratumumab, a Novel CD38 Monoclonal Antibody, in Myeloma. Drugs. 2016; 76:853-67. https://doi.org/10.1007/s40265-0160573-4. [PubMed]

60. Avet-Loiseau H, Hulin C, Campion L, Rodon P, Marit G, Attal M, Royer B, Dib M, Voillat L, Bouscary D, Caillot D, Wetterwald M, Pegourie B, et al. Chromosomal abnormalities are major prognostic factors in elderly patients with multiple myeloma: The Intergroupe Francophone du Myélome experience. J Clin Oncol. 2013; 31:2806-2809. https://doi.org/10.1200/JCO.2012.46.2598. [PubMed]

61. Sonneveld P, Avet-Loiseau H, Lonial S, Usmani S, Siegel D, Anderson KC, Chng WJ, Moreau P, Attal M, Kyle RA, Caers J, Hillengass J, San Miguel J, et al. Treatment of multiple myeloma with high-risk cytogenetics: a consensus of the International Myeloma Working Group. Blood. 2016; 127:2955-2962. https://doi.org/10.1182/ blood-2016-01-631200. [PubMed]

62. Palumbo A, Bringhen S, Falco P, Cavallo F, Ambrosini MT, Avonto I, Gay F, Caravita T, Bruno B, Boccadoro M. Time to first disease progression, but not b2-microglobulin, predicts outcome in myeloma patients who receive thalidomide as salvage therapy. Cancer. 2007; 110:824-829. https://doi.org/10.1002/cncr.22855. [PubMed]

63. Shah N, Ahmed F, Bashir Q, Qureshi S, Dinh Y, Rondon G, Wen S, Thall P, Khan H, Giralt S, Champlin R, Qazilbash $\mathrm{MH}$. Durable remission with salvage second autotransplants in patients with multiple myeloma. Cancer. 2012; 118:354955.. https://doi.org/10.1002/cncr.26662. [PubMed]

64. Yong K, Delforge M, Driessen C, Fink L, Flinois A, Gonzalez-McQuire S, Safaei R, Karlin L, Mateos MV, Raab MS, Schoen P, Cavo M. Multiple myeloma: patient outcomes in real-world practice. Br J Haematol. 2016; 175:252-264. https://doi.org/10.1111/bjh.14213. [PubMed]

65. Leukemia \& Lymphoma Society. Myeloma Oral Treatment Adherence Facts. Leukemia \& Lymphoma Society. http:// www.1ls.org.

66. Sweiss K. Oral Antimyeloma Therapy: Barriers to Patient Adherence and Tips for Improvement. HOPA NEWS. 2018. http://www.hoparx.org/hopa-news/volume-15-issue-3-2018/ oral-antimyeloma-therapy-barriers-to-patient-adherenceand-tips-for-improvement.

67. Wilke T, Mueller S, Bauer S, Pitura S, Probst L, Ratsch BA, Salwender H. Treatment of relapsed refractory multiple myeloma: which new PI-based combination treatments do patients prefer? Patient Prefer Adherence. 2018; 12:23872396. https://doi.org/10.2147/PPA.S183187. [ubMed]

68. Rifkin RM, Bell JA, DasMahapatra P, Hoole M, Lowe M, Curran C, Campbell S, Hou P, Romanus D. Treatment Satisfaction and Burden of Illness in Patients with Newly Diagnosed Multiple Myeloma. Pharmacoeconom Open. 2020; 4:473-483. https://doi.org/10.1007/s41669-01900184-9. [PubMed]
69. Gupta S, Abouzaid S, Liebert R, Parikh K, Rosenberg AS. Assessing the Effect of Injectable or Oral Routes of Treatment Administration on Patient-Reported Outcomes and out-of-Pocket Costs Among Patients with Multiple Myeloma. Blood. 2016; 128:5931-5931. https://doi. org/10.1182/blood.V128.22.5931.5931.

70. Moreau P, Mateos MV, Berenson JR, Weisel K, Lazzaro A, Song K, Dimopoulos MA, Huang M, Zahlten-Kumeli A, Stewart AK. Once weekly versus twice weekly carfilzomib dosing in patients with relapsed and refractory multiple myeloma (A.R.R.O.W.): interim analysis results of a randomised, phase 3 study. Lancet Oncol. 2018; 19:953964. https://doi.org/10.1016/S1470-2045(18)30354-1. [PubMed]

71. Bhatnagar V, Gormley NJ, Luo L, Shen YL, Sridhara R, Subramaniam S, Shen G, Ma L, Shord S, Goldberg KB, Farrell AT, McKee AE, Pazdur R. FDA Approval Summary: Daratumumab for Treatment of Multiple Myeloma After One Prior Therapy. Oncologist. 2017; 22:1347-1353. https://doi.org/10.1634/theoncologist.2017-0229. [PubMed]

72. Barr H, Dempsey J, Waller A, Huang Y, Williams N, Sharma N, Benson DM, Rosko AE, Efebera YA, Hofmeister CC. Ninety-minute daratumumab infusion is safe in multiple myeloma. Leukemia. 2018; 32:2495-2518. https://doi. org/10.1038/s41375-018-0120-2. [PubMed]

73. Bristol-Myers Squibb Farmacêutica, LTDA. Empliciti (Elotuzumab). Bula. 2017. https://www.bms.com/assets/ bms/brazil/documents/hcp/bula-profissional-saude/ EMPLICITI_PO\%20LIO\%20SOL\%20INJ_VPS_Rev0717new.pdf.

74. Chari A, Vogl DT, Gavriatopoulou M, Nooka AK, Yee AJ, Huff CA, Moreau P, Dingli D, Cole C, Lonial S, Dimopoulos M, Stewart AK, Richter J, et al. Oral SelinexorDexamethasone for Triple-Class Refractory Multiple Myeloma. N Engl J Med. 2019; 381:727-738. https://doi. org/10.1056/NEJMoa1903455. [PubMed]

75. Wu Z, McGoogan JM. Characteristics of and Important Lessons From the Coronavirus Disease 2019 (COVID-19) Outbreak in China: Summary of a Report of 72314 Cases From the Chinese Center for Disease Control and Prevention. JAMA. 2020; 323:1239-1242. https://doi. org/10.1001/jama.2020.2648. [PubMed]

76. Zhou F, Yu T, Du R, Fan G, Liu Y, Liu Z, Xiang J, Wang Y, Song B, Gu X, Guan L, Wei Y, Li H, et al. Clinical course and risk factors for mortality of adult inpatients with COVID-19 in Wuhan, China: a retrospective cohort study. Lancet. 2020; 395:1054-1062. https://doi.org/10.1016/ S0140-6736(20)30566-3. [PubMed]

77. Onder G, Rezza G, Brusaferro S. Case-Fatality Rate and Characteristics of Patients Dying in Relation to COVID-19 in Italy. JAMA. 2020; 323:1775-1776. https://doi. org/10.1001/jama.2020.4683. [PubMed]

78. Burki TK. Cancer guidelines during the COVID-19 pandemic. Lancet Oncol. 2020; 21:629-630. https://doi. org/10.1016/S1470-2045(20)30217-5. [PubMed] 
79. EBMT. Coronavirus Disease COVID-19: EBMT Recommendations. EBMT. 2020. https://www.ebmt.org/ sites/default/files/2020-04/EBMT-COVID-19-guidelines V.6.1\%282020-04-07\%29.pdf.

80. Rajkumar V, Cavo M, Mikhail J, Mateos MM, Jackson G, Moreau P, Richardson P, Dhakal B. COVID-19 and Multiple Myeloma: Frequently Asked Questions [Internet]. American Society Of Hematology. 2020. p. Version 1.1, last updated April 23. https://www.hematology.org/covid-19/ covid-19-and-multiple-myeloma.

81. Malard F, Mohty M. Management of patients with multiple myeloma during the COVID-19 pandemic. Lancet Haematol. 2020; 7:e435-e437. https://doi.org/10.1016/ S2352-3026(20)30124-1. [PubMed]

82. Lawton MP, Brody EM. Assessment of older people: Selfmaintaining and instrumental activities of daily living. Gerontologist. 1969; 9:179-186. https://doi.org/10.1093/ geront/9.3 Part 1.179. [PubMed]

83. Charlson ME, Pompei P, Ales KL, MacKenzie CR. A new method of classifying prognostic comorbidity in longitudinal studies: Development and validation. J Chronic
Dis. 1987; 40:373-383. https://doi.org/10.1016/00219681(87)90171-8.

84. Katz S, Ford AB, Moskowitz RW, Jackson BA, Jaffe MW. Studies of Illness in the Aged: The Index of ADL: A Standardized Measure of Biological and Psychosocial Function. JAMA. 1963; 185:914-9. https://doi.org/10.1001/ jama.1963.03060120024016. [PubMed]

85. Kumar S, Paiva B, Anderson KC, Durie B, Landgren O, Moreau P, Munshi N, Lonial S, Bladé J, Mateos MV, Dimopoulos M, Kastritis E, Boccadoro M, et al. International Myeloma Working Group consensus criteria for response and minimal residual disease assessment in multiple myeloma. Lancet Oncol. 2016; 17:e328-e346. https://doi.org/10.1016/S1470-2045(16)30206-6. [PubMed]

86. Chim CS, Kumar SK, Orlowski RZ, Cook G, Richardson PG, Gertz MA, Giralt S, Mateos MV, Leleu X, Anderson KC. Management of relapsed and refractory multiple myeloma: Novel agents, antibodies, immunotherapies and beyond. Leukemia. 2018; 32:252-62. https://doi. org/10.1038/leu.2017.329. [PubMed] 